\title{
INFLUENCE OF FEED RESTRICTION METHOD AND SEASON ON THE CHEMICAL COMPOSITION OF MEAT IN KOEKOEK CHICKENS
}

\author{
Setsumi Motsoene MOLAPO ${ }^{1 \times}$ and Edward WEBB ${ }^{2}$ \\ 1 Department of Animal Science, National University of Lesotho, P.O. Roma 180, Lesotho \\ 2 Department of Animal and Wildlife Sciences, University of Pretoria, Pretoria 0002, South Africa \\ Emails: setsomimolapo@gmail.com; sm.molapo@nul.Is; (1) ORCiD: 0000-0002-4426-8901 \\ Supporting Information
}

\begin{abstract}
The main objective of the study was to determine the effect of restricted feeding and season on carcass chemical composition of Koekoek chickens. Two hundred and seventy hens and 27 cocks were used. The experiment was designed as a factorial of two seasons and four feeding regime treatments. The four treatments were consisted of chickens full-fed during both rearing and laying phases (AA), those shifted to restricted feeding during the laying phase (AR), birds fed restrictedly during the rearing phase and shifted to full feeding in the laying phase (RA) and those fed restrictedly during both rearing and laying phases (RR). Each treatment had seven replicates (10 birds per replicate) with an exception of RR treatment which was replicated six times (10 birds per replicate). Data was collected at 18 and 32 weeks of age. Data collected was subjected to SPSS (17.00) statistical package and analyzed by using multi- factorial analysis of variance (ANOVA). At the age of 18 weeks, feed restriction had an impact on dry matter, fat and crude protein percentage. At 32 weeks of age, birds that were fed restrictedly had reduced fat content and increased crude protein. The lowest crude protein percentage was recorded in chickens that were allocated to full feeding for the entire study (AA). Chickens that were allotted to summer treatment had a higher dry matter and crude protein content than chickens that were in winter treatment at 18 weeks of age. Koekoek chickens that were in summer and winter treatments performed differently in terms dry matter, ash, crude fat and crude protein percentages at the age of 32 weeks. Based on the findings of this study it is concluded that chickens with higher slaughter weights resulted in a lower crude protein and higher amount of fat regardless of the slaughter age. Chicken meat that was produced in winter had a higher dry matter and crude protein content compared to that produced in summer at the slaughter age of 18 weeks. In the laying phase the meat of Koekoek chickens that were reared in winter had a higher dry matter, ash, fat and crude protein percentages than that of chickens produced in summer suggesting that the cold winter conditions have the potential to preserve the nutrient composition of chicken meat.
\end{abstract}

Keywords: Chemical composition, Feed restriction, Koekoek chickens, Temperature.

\section{INTRODUCTION}

Currently, high cost of poultry products makes it impossible for an average person in the country to consume an adequate quantity of animal protein. These price increases are a reflection of corresponding high costs of feeds which result in low production and short supply of poultry. Quantitative feed restriction early in rearing reduces the dry matter and crude protein percentage of meat in birds (Arrazola et al., 2019; Algam et al., 2020). The ash content was reported to be similar in ad libitum and restricted fed chickens (Renema et al., 1999; Farghly et al., 2019). Renema et al. (2007) explained that the percentage of crude fat in poultry meat is dependent on the severity of early feed restriction. In a study conducted by Crounch et al. (2002) it was observed that carcass fat was reduced in restricted-fed turkeys.

Higher moisture content was reported in chickens meat produced during the summer (Bianchi et al., 2007). However, the results of Akşit et al. (2006) suggest lower moisture content in thighs chickens that were reared under increased environmental temperature while Barbour et al. (2010) reported non-significant differences between the two groups of chickens. Summer conditions retarded the protein content in chickens Akşit et al., 2006 and Bianchi et al., 2007). Barbour et al. (2010) reported that environmental temperature did not affect the dry matter content. Akşit et al. (2006) reported that the ash content is negatively correlated to the level of temperature. Bianchi et al. (2007) also reported a lower ash percentage in summer reared chickens as against the ones produced during the winter season. Carcass fat was higher in chickens that were exposed to higher temperatures or summer conditions (Bianchi et al., 2007; Rosa et al., 2007; Barbour et al., 2010; Zaboli et al., 2019).

In order to have a meaningful and sustainable poultry production, it is necessary to study the means of producing an acceptable quality of chicken meat at reduced costs in different seasons. An alternative feed management practice that addresses this issue it is important and that is why this research project focused on the effects of feed restriction and season on carcass chemical composition of Koekoek chickens. With the research information obtained from this study, the farmers would be able to choose the appropriate feeding level and season so as to reduce the feeding costs without compromising the quality of meat from Koekoek chickens. 
Two hundred and seventy hens and twenty seven cocks of Koekoek chickens were bought at eight weeks of age. Ten hens and one cock were randomly selected and placed in each pen. The chickens were given stress pack in water to combat traveling stress and lasoda vaccine to prevent Newcastle disease. They were fed pullet grower mash from arrival day up to 18 weeks of age, and then fed laying mash from 19 to 32 weeks. Koekoek chickens under restricted feeding were fed $70 \%$ of full feeding. Koekoek chickens were offered fresh water without restriction and fed the same commercial feeds but at different quantities per day. The experiment was designed as a 4 feeding levels $\times 2$ seasons (summer and winter) factorial arrangement in a completely randomized design. Treatments comprised: AA (chickens full-fed during both rearing and laying phases), AR (chickens full-fed during the rearing phase and shifted to restricted feeding during the laying phase), RA (chickens fed restrictedly during the rearing phase and shifted to full feeding in the laying phase) and RR (chickens fed restrictedly during both rearing and laying phases). Treatments AA, AR and RA were replicated seven times except treatment RR which was replicated six times. Therefore, there were twenty seven experimental units.

At 18 and 32 weeks of age, one Koekoek chicken per replicate was slaughtered from chickens that were allocated to AA, AR, RA and RR treatments. Birds were starved for 12 hours before slaughtering. The slaughtering procedure was followed as outlined by Jones (1984). Following the weighing and measuring of organs and tissues, they were returned to their respective individual carcasses and stored at $-40^{\circ} \mathrm{C}$. The carcass composition was carried out on birds without feathers with all carcass components. Thawed carcasses were dissected and then be emptied into the blender (mincer) to be homogenized. The duplicate sample $(200 \mathrm{~g})$ of each homogenate was freeze dried and then ground. The ground sample was then chemically analyzed for dry matter, protein, fat, and ash (Van Marle-Köster and Webb, 2000).

Data obtained and collected were stored in the computer under Microsoft excel and then finally analyzed using multi factorial analysis of variance with the aid of SPSS (17.00) statistical package. The same study was done in two different seasons being the summer and winter.

\section{Ethical approval}

The Department of Animal Science of the National University scientific and ethics committee approved the study protocol.

\section{RESULTS AND DISCUSSION}

The findings of this study as illustrated in Table 1 revealed that Koekoek chickens which were full-fed in the rearing phase had the dry matter content of $96.66 \%$ and $96.85 \%$ for chickens that were in AA and AR treatments respectively while chickens that were subjected to restricted feeding had dry matter content of $89.14 \%$ and $90.07 \%$ for chickens in RA and RR treatments respectively at 18 weeks of age. The dry matter content of chickens that were in full feeding was higher $(p<0.05)$ than the one in feed restricted chickens by 7.39 percent.

At the age of 32 weeks, there were no significant differences observed in the dry matter content of chickens that were subjected to different treatments except for chickens that were in AA treatment. Koekoek chickens that were full-fed for the entire study $(A A)$ had lower $(P<0.05)$ dry matter content $(95.17 \%)$ as compared to chickens that were in AR, RA and RR treatments with dry matter contents of $95.87 \%, 95.99 \%$ and $95.95 \%$ respectively. The chickens in AR, RA and RR treatments were not different $(P>0.05)$ in terms of dry matter content. The findings of this study clearly indicated that the dry matter content failed to respond positively to body weight in chickens that were in AA treatment at 32 weeks of age. It was also observed that the dry matter content of chickens that were full-fed in the rearing phase (AA and AR) declined during the laying phase while the dry matter of chickens that were feed restricted during the rearing phase (RA and RR) increased in the laying phase.

Table 1 - Dry matter, ash, crude fat and crude protein percentages of meat from Koekoek chickens that were subjected to different feeding level treatments

\begin{tabular}{|c|c|c|c|c|c|c|}
\hline $\begin{array}{ll}\text { Age wks } & \text { Treatments }\end{array}$ & Nutrient (\%) & AA & AR & RA & RR & S.E \\
\hline \multirow{4}{*}{18} & DM & $96.66^{a}$ & $96.85^{a}$ & $89.14^{b}$ & $90.07^{b}$ & 0.24 \\
\hline & Ash & 8.65 & 8.61 & 8.56 & 8.23 & 0.11 \\
\hline & Fat & $43.44^{a}$ & $41.53^{a}$ & $33.47^{b}$ & $32.72^{b}$ & 0.47 \\
\hline & $\mathrm{CP}$ & $37.94^{a}$ & $40.75^{a}$ & $49.98^{b}$ & $50.79^{b}$ & 0.57 \\
\hline \multirow{4}{*}{32} & DM & $95.17^{a}$ & $95.87^{b}$ & $95.99^{b}$ & $95.95^{b}$ & 0.10 \\
\hline & Ash & 6.13 & 6.17 & 6.06 & 6.32 & 0.15 \\
\hline & Fat & $51.90^{a}$ & $45.25^{b}$ & $50.20^{a}$ & $40.02^{c}$ & 0.69 \\
\hline & $\mathrm{CP}$ & $39.71^{a}$ & $41.93^{a b}$ & $41.77^{a b}$ & $45.14^{b}$ & 0.67 \\
\hline
\end{tabular}


These results are in agreement with the results of Robinson et al. (1991) who reported a significantly higher dry matter percentage in ad libitum fed chickens than in restricted fed chickens. The carcass ash contents of chickens were

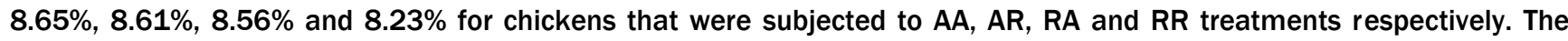
results on the carcass ash percentage did not differ $(P>0.05)$ between chickens that were allocated to different feeding treatments. In spite of insignificant differences between chickens that were subjected to different treatments, Koekoek chickens that were full-fed (AA and AR) had higher carcass ash content than their counterparts by 2.67 percent. This insignificant differences showed that the carcass ash content was not related to the slaughter weight hence a nonsignificant correlation $(r=0.076)$ between ash content and slaughter weight.

At the age of 32 weeks the meat ash percentage was higher (6.32\%) in chickens there were allotted to restricted feeding for both rearing and laying phases (RR) as compared to the ash content of chickens that were in AA, AR and RA treatments with the ash percentages of $6.13 \%, 6.17 \%$ and $6.06 \%$ respectively. These results pointed out that chickens that were feed restricted for a longer period had higher carcass ash content. The findings of this study showed that the higher the slaughter weight the lower the ash content in Koekoek chickens at the age of 32 weeks. The ash percentage had insignificant negative correlation $(r=-0.110)$ with the slaughter weight. The carcass ash content had no significant correlation with crude protein, fat and dry matter percentages. This means that the ash content cannot be estimated by relating it either with body weight or any of the nutrients. The results also revealed a decline of $27.50 \%$ in ash content across all treatments from 18 to 32 weeks of age meaning that the older the chickens the lesser the ash content.

Renema et al. (1999) also reported the similar ash content between full fed and restricted fed chickens. Koekoek chickens that were allocated to full feeding and restricted feeding had different carcass fat percentages. An average crude fat percentage of chickens that were full-fed (AA and AR) was higher ( $P<0.05 ; 42.49 \%)$ than the ones of Koekoek chickens that were feed restricted (RA and RR) with an average fat content of $33.10 \%$. The findings implied that heavier chickens at slaughter age had higher crude fat percentage. This can be clearly confirmed by the positive $(p<0.01)$ correlation $(r=0.635)$ between slaughter weight and crude fat percentage. The crude fat percentage also had a positive correlation $(r=0.682)$ with the dry matter percentage while the opposite was true with the crude protein percentage $(r=-$ $0.627 ; p<0.01)$.

At the age of 32 weeks, the crude fat percentages of Koekoek chickens that were full-fed (AA and RA) were different $(p<0.05)$ from crude fat percentages of birds that were under feed restriction (AR and RR). Birds that were in AA treatment had higher fat content of $\mathbf{5 1 . 9 0 \%}$ and they were not significantly different from Koekoek chickens that were in RA treatment with the crude fat content of 50.20 percent. The lowest $(p<0.05)$ percentage $(40.02 \%)$ of the crude fat was recorded in Koekoek chickens that were in RR treatment followed by chickens that were subjected to AR treatment with 45.25 percent. It was also observed that the crude fat content increased as chickens were getting older across all the feeding level treatments. Chickens in RA treatment had the highest increase with reference to crude fat as compared to crude fat content of chickens in other treatments while chickens in AR treatment had the lowest fat accumulation from 18 to 32 weeks of age. The highest crude fat percentage obtained from chickens that were in RA treatment can possibly be attached to the compensatory growth shown by the same group of chickens. The crude fat percentages increased by $16.30 \%, 8.22 \%, 33.33 \%$, and $18.24 \%$ for chickens that were in AA, AR, RA and RR treatments respectively.

The results of this study are in accord with the findings of Renema et al. (1999) who stated that the higher crude fat content was found in birds that had heavy body weights compared to lower body weights chickens. Crounch et al. (2002) also indicated that turkeys that were feed restricted had lower crude fat during the rearing when compared to the ones that were full fed. These results were also supported by Hassanabadi and Moghaddam (2004) who concluded that carcass fat content of restricted fed birds was lower $(p<0.05)$ than of control fed birds. Renema et al. (1999) also indicated that carcass lipid remained significantly greater in ad libitum fed birds than in restricted fed birds.

The results of this study as depicted in Table 1 indicated that crude protein percentage of birds that were under full feeding were different $(p<0.05)$ from the one of the birds that were under restricted feeding during rearing phase. Koekoek chickens that were full-fed obtained a lower percentage of crude protein (39.35\%) while birds that were raised under feed restriction had crude protein of $\mathbf{5 0 . 3 9}$ percent. This indicated that an average crude protein percentage of restricted fed chickens was higher than the one of full-fed chickens by 21.91 percent. These results evidently illustrated that chickens with high body weight and fat content had reduced crude protein content hence why the crude protein is negatively correlated $(p<0.01)$ with the body slaughter weight $(r=-0.467)$, crude fat content $(r=-0.627)$, dry matter content $(r=-0.553)$ and ash $(r=-0.295 ; p<0.05)$.

At the age of 32 weeks Koekoek chickens that were full-fed for the entire study (AA) obtained lower $(p<0.05)$ percentage of crude protein (39.71\%) than chickens that were exposed to feed restriction for the entire study (RR) which had highest protein content (45.14\%). The crude protein percentages of Koekoek chickens that were in AR (41.93\%) and RA (41.77\%) treatments were statistically $(p>0.05)$ similar and were different $(p<0.05)$ from chickens that were in AA and RR treatments. The results also showed a negative $(p<0.01)$ correlation $(r=-0.547)$ between the slaughter weight and crude protein.

The findings of this study disclosed that the crude protein percentage of chickens that were initially on full feeding in the rearing and later shifted to restricted feeding during the laying phase ( $A R$ ) increased by $2.81 \%$ while the one of chickens that were fed restrictedly during rearing and full-fed during laying ( RA) declined drastically by 16.42 percent. Koekoek chickens that were full-fed for the two phases increased their protein content by $5.21 \%$ from 18 to 32 weeks of age. The protein percentage of chickens that were exposed to restricted feeding for the whole study (RR) decreased by 
11.12\%. These results indicated that despite chickens in restricted feeding having higher protein content there is a possibility of a decline in the crude protein percentage if they are slaughtered at an older age. This was also confirmed by De Beer and Coon (2007) who stated that the carcass protein content generally decreases as chicken age increases. The results from this study are related to the findings of Renema et al. (1999) who reported the similar percentages of protein in chickens that were in different feeding regimes of which the similar fashion of results was observed in this study at 32 weeks of age since chickens in AA, AR and RR had statistically similar carcass protein contents.

The results in Table 2 show that the dry matter percentage of meat from Koekoek chickens that were reared in two different seasons was significant. Chickens that were kept during summer season had higher $(p<0.05)$ dry matter (94.12\%) than the ones that were allocated to winter conditions with 92.24 percent. This showed that dry matter content of chickens that were reared in summer was $2 \%$ higher than the one of chickens that were kept in winter.

During the laying phase (32 weeks) there was a significant difference in the percentage of dry matter observed between Koekoek chickens that were reared in summer and winter seasons. Birds in summer season had a higher $(p<0.05)$ dry matter $(96.20 \%)$ compared to birds that were raised in winter season which had the dry matter content of 95.29\%. These results showed that cold winter condition hindered the dry matter content by almost one percent. It was also observed that the dry matter content increased with the increase in age. This can be confirmed by the fact that the dry matter content increased by $2.16 \%$ and $3.20 \%$ in chickens that were exposed to summer and winter conditions respectively between 18 and 32 weeks of age. This is clearly indicating that the higher dry matter content in chickens that were kept in summer was possibly due to the higher weights that chickens experienced in summer.

The results of this study are in accordance with the findings of Akşit et al. (2006) who noted that chickens that were raised under higher temperature had lower moisture content compared to the ones that were raised under lower temperatures. Contrary to the results of this study, Chen et al. (2007) found no differences between the moisture content of chickens that were subjected to different number of sunlight hours in a day. Barbour et al. (2010) also reported the non-significant differences in the moisture content of chickens that were exposed to different temperatures. In contradicting with the findings of the current study, Bianchi et al. (2007) concluded that chicken meat produced in summer would have higher content of moisture.

Table 2 - Dry matters, ash, crude fat and crude protein percentages of meat from Koekoek chickens that were reared either in summer or winter season

\begin{tabular}{|c|c|c|c|c|}
\hline Age wks $\quad$ Season & Nutrient (\%) & Summer & Winter & S.E \\
\hline \multirow{4}{*}{18} & DM & $94.12^{\mathrm{a}}$ & $92.24^{b}$ & 0.48 \\
\hline & Ash & 8.50 & 8.52 & 0.21 \\
\hline & Fat & 37.72 & 37.86 & 0.94 \\
\hline & $\mathrm{CP}$ & $46.43^{a}$ & $43.29 b$ & 1.15 \\
\hline \multirow{4}{*}{32} & DM & $96.20^{a}$ & $95.29^{b}$ & 0.19 \\
\hline & Ash & $6.03^{a}$ & $6.31^{a}$ & 0.30 \\
\hline & Fat & $45.22^{a}$ & $48.47^{b}$ & 1.37 \\
\hline & $\mathrm{CP}$ & $38.04^{a}$ & $46.24^{b}$ & 1.36 \\
\hline
\end{tabular}

The results as shown in Table 3 demonstrated that there was an interaction $(p<0.01)$ between feeding level and season on the dry matter content of Koekoek only at the slaughter age of 18 weeks. The results portrayed that the percentage of the dry matter in chickens that were subjected to restricted feeding in winter (WRA and WRR) was $4.13 \%$ less than the one of chickens that were feed restricted during summer season (SRA and SRR). With references to chickens that were full-fed, it was established that the dry matter content was similar with $96.74 \%$ and $96.78 \%$ for chickens that were in summer and winter seasons respectively. The feeding level and season interactive results clearly showed that the differences in the dry matter were mainly due to the different slaughter weights that were noticed to be higher in summer season at the age of 18 weeks.

At the age of 18 weeks (rearing phase) as shown in Table 2 it was observed that chickens that were kept in summer and winter seasons obtained similar $(p>0.05)$ meat ash contents. The ash content of chickens reared in summer and winter seasons were $\mathbf{8 . 5 0 \%}$ and $\mathbf{8 . 5 2 \%}$ respectively. During the laying phase (32 weeks) chicken meat ash percentages were $6.03 \%$ and $6.31 \%$ for chickens that were in summer and winter treatments respectively. These results indicated that cold winter conditions boosted the content of ash by 4.44 percent. This clearly showed that the ash content was negatively associated with the slaughter weight of chickens. It was also observed that the meat ash content decreased with an increase in age. The ash content of meat from chickens that were subjected to summer treatment deteriorated by $29.06 \%$ and the one from chickens that were kept in winter declined by $25.95 \%$ from 18 to 32 weeks of age. This evidently showed that the meat ash quality was negatively affected by high temperatures in summer than low temperatures in winter meaning that low temperatures were able to preserve the mineral and the vitamin components in chicken meat.

The results of this study are in line with the findings Akşit et al. (2006) who reported that the ash content seemed to decrease with an increase in age. The results by Bianchi et al. (2007) also stated that chickens meat produced in winter had a higher ash content compared to the one produced in summer. Persia et al. (2003) found that the tibia ash percentage in chickens' meat was not affected by the high temperature and this was not in agreement with the finding of this study. In contradicting with the results of the current study Chen et al. (2007) disclosed that the relative ash percentage is not influenced by the different photoperiods. 
Table 3 - Effect of feeding level and season on the chemical composition of meat from Koekoek chickens

\begin{tabular}{|c|c|c|c|c|c|c|c|c|c|c|c|c|c|c|c|c|}
\hline $\begin{array}{l}\text { Meat chemical } \\
\text { composition }\end{array}$ & SAA & S.E & WAA & S.E & SAR & S.E & WAR & S.E & SRA & S.E & WRA & S.E & SRR & S.E & WRR & S.E \\
\hline$\% \mathrm{DM}$ & $96.96^{a}$ & 0.62 & $96.36^{b}$ & 0.62 & $96.52^{a}$ & 0.62 & $97.19^{b}$ & 0.62 & $91.67^{a}$ & 0.62 & $86.61^{b}$ & 0.62 & $91.33^{a}$ & 0.67 & $88.82^{b}$ & 0.62 \\
\hline$\%$ Ash & 8.48 & 0.22 & 8.82 & 0.22 & 8.71 & 0.22 & 8.51 & 0.22 & 8.40 & 0.22 & 8.72 & 0.22 & 8.42 & 0.24 & 8.03 & 0.24 \\
\hline$\%$ Fat & 43.45 & 1.30 & 43.42 & 1.30 & 43.08 & 1.30 & 39.98 & 1.30 & 32.87 & 1.30 & 34.07 & 1.30 & 31.47 & 1.41 & 33.97 & 1.41 \\
\hline$\% \mathrm{CP}$ & 39.36 & 1.41 & 36.52 & 1.41 & 42.30 & 1.41 & 39.19 & 1.30 & 53.47 & 1.41 & 46.48 & 1.41 & 50.60 & 1.52 & 50.98 & 1.41 \\
\hline$\% \mathrm{DM}$ & 96.05 & 0.27 & 94.30 & 0.27 & 96.29 & 0.27 & 95.45 & 0.27 & 96.30 & 0.27 & 95.69 & 0.27 & 96.18 & 0.29 & 95.72 & 0.29 \\
\hline$\%$ Ash & 5.88 & 0.41 & 6.38 & 0.41 & 5.46 & 0.41 & 6.89 & 0.41 & 6.12 & 0.41 & 5.99 & 0.41 & 6.65 & 0.44 & 5.99 & 0.44 \\
\hline$\%$ Fat & 47.76 & 1.88 & 56.04 & 1.88 & 42.97 & 1.88 & 47.53 & 1.88 & 49.67 & 1.88 & 50.73 & 1.88 & 40.48 & 2.05 & 39.56 & 2.05 \\
\hline$\% \mathrm{CP}$ & 35.70 & 1.86 & 43.72 & 1.86 & 39.93 & 1.86 & 43.94 & 1.86 & 35.76 & 1.86 & 47.78 & 1.86 & 40.75 & 2.01 & 49.52 & 2.01 \\
\hline
\end{tabular}

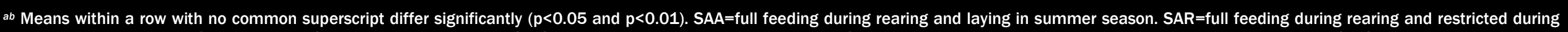

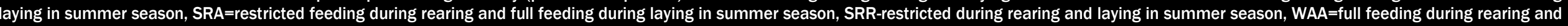

aying in winter season. WAR=full feeding during rearing and restricted during laying in winter season, WRA=restricted feeding during rearing and full feeding during laying in winter season, WRR=restricted durin

rearing and laying in winter season, S.E=standard error, Sig=Significance level. \%DM=Percentage Dry matter, \% Ash=Percentage Ash, \%Fat=Percentage fat, \%CP=Percentage crude protein. 
During the rearing phase (18 weeks) the fat percentages were statistically similar $(p>0.05)$ between the summer and winter seasons. The results in Table 2 depicted that chickens reared in summer season had insignificantly higher crude fat percentage (37.86\%) than winter reared chickens which had the fat content of 37.72 percent. The differences $(p<0.05)$ in the percentage of crude fat were observed at the age of 32 weeks between chickens that were reared in summer and winter seasons. Koekoek chickens that were in winter treatment outperformed their counterparts by $6.71 \%$ with reference to crude fat content. The crude fat percentage seemed to increase with age despite of season in which chickens were produced. Chickens that were subjected to summer conditions managed to accumulate $7.72 \%$ while the ones raised in winter conditions accumulated $10.61 \%$ of the crude fat between 18 and 32 weeks of age.

The results in the rearing phase (18 weeks) are supported by the findings of Chen et al. (2007) who reported the non-significant differences in the total fat content of chickens that were subjected to different photoperiods. On the other hand, Bianchi et al. (2007) and Bogosavljević-Bosković et al. (2006) stated higher lipid content in chickens that were kept in summer as opposed to the ones kept in winter. Barbour et al. (2010) also confirmed that birds that were heat acclimatized had higher percentage of fat than the ones that were not exposed to heat. The higher crude fat percentage in chickens that were raised in winter is believed to be the outcome of high feed intake and as a result they were able to accumulate more fat.

At the age of 18 weeks as demonstrated in Table 2 the results illustrated that chickens that were in summer treatment had higher $(p<0.05)$ crude protein content $(46.43 \%)$ compared to chickens that were kept in winter season (43.29\%). Koekoek chickens that were in summer treatment were $6.76 \%$ higher than the winter reared chickens with respect to crude protein percentage. At this phase of production, the protein content seemed to respond positively to the body weight of chickens since the higher slaughter weights that were experienced during the summer season resulted in a higher crude protein content. The opposite pattern of the results was observed in chicken meat at the slaughter age of 32 weeks. Koekoek chickens that were exposed to winter conditions had higher $(p<0.05)$ crude protein content $(46.24 \%)$ as compared to the ones that were subjected to summer treatment (38.04\%). Koekoek chickens with higher body weights had lower crude protein percentages. It was also observed that the meat crude protein content of chickens that were exposed to warm summer condition declined by $18.07 \%$ over a period of 14 weeks while the protein content of chickens that were reared in winter increased by 6.38 percent. These results reflected that the meat of chickens produced in summer deteriorate in value as chickens get older while the opposite is true with the chickens raised in winter.

The results from this study are supported by the findings of Bianchi et al. (2007) and Blahova et al. (2007) who pointed out that the protein level was lower in chicken meat that was produced in summer of which it was the case in this study especially at the slaughter age of 32 week. Akşit et al. (2006) and Rosa et al. (2007) also argued that the protein content corresponded negatively with the amount of heat allotted to chickens. Contrary to the findings of this study other researchers reported the similar performance in chickens that were exposed to different temperatures (Chen et al., 2007; Barbour et al., 2010).

\section{CONCLUSION}

Chickens with higher slaughter weights resulted in a lower crude protein and higher amount of fat in the regardless of the slaughter age. Chicken meat that was produced in winter had a higher dry matter and crude protein content compared to that produced in summer at the slaughter age of 18 weeks. In the laying phase the meat of Koekoek chickens that were reared in winter had a higher dry matter, ash, fat and crude protein percentages than that of chickens produced in summer suggesting that the cold winter conditions have the potential to preserve the nutrient composition of chicken meat. In order to have chicken meat with higher a protein content and low fat content it is recommended that Koekoek chickens be raised on feed restriction (RR) if a farmer is aiming at producing meat from either 18 or 32 weeks old chickens. The meat produced from chickens that were in RA and AR treatments cannot be ruled out because of its higher crude protein except that it cannot be recommended to people who cannot eat meat with more fat. It is also recommended that the best season to rear Koekoek chickens is summer if the target is to slaughter them at the age of 18 weeks based on the higher crude protein and dry matter contents. In a case where chickens would be slaughtered at an older age (32 weeks) it would be advantageous to keep Koekoek chickens in winter so as to obtain higher ash (mineral and vitamin content) and crude protein percentages.

\section{DECLARATION}

Corresponding author

E-mails: sm.molapo@nul.Is; setsomimolapo@gmail.com

Authors' contribution

The two authors contributed in developing the content of this manuscript.

Availability of data

The data can be availed to the journal upon request. 
Consent to publish

Not applicable

\section{Conflict of interest}

The authors declare they have no competing of interests.

\section{Acknowledgement}

The authors would wish to acknowledge the Department of Animal Science of the National University of Lesotho for their support through the whole process of developing this publication.

\section{REFERENCES}

Akşit M, Yalcin S, Özkan S, Metin K, Özdemir D (2006). Effects of temperature during rearing and crating on stress parameters and meat quality of broilers. Poultry Science. 85(11): 1867-74. Google Scholar I Doi: https://doi.org/10.1093/ps/85.11.1867

Algam TA, Osman RH, Zomrawi WB and Abdalhag MA (2020). Effect of phase feeding on broiler performance. Online Journal of Animal and Feed Research, 10(1): 36-40. DOI: https://dx.doi.org/10.36380/scil.2020.ojafr5 I Link

Arrazola A, Mosco E, Widowski TM, Guerin MT, Kiarie EG, and Torrey S (2019). The effect of alternative feeding strategies for broiler breeder pullets: 1. Welfare and performance during rearing. Poultry Science, 98(9): 3377-3390. Google Scholar I Doi: https://doi.org/10.3382/ps/pez170

Barbour EK, Tayeb I, Shaib H, and Abrahim IM (2010). Physiological and carcass traits in heat stressed broilers differing in heat acclimatization, chemical or feed restriction treatments. Agriculture and Biology journal of North America. 1(2): 65-74. Google Scholar I Link

Bianchi M, Petracci M, Sirri F, Folegatti E, Franchini A, and Melazzi A (2007). The influence of season and market class of broiler chickens on breast meat quality traits. Poultry Science, 86(5): 959-963. Google Scholar I Doi: https://doi.org/10.1093/ps/86.5.959

Blahova J, Dobsikova R, Strakova E, and Suchy P (2007). Effect of low environment temperature on performance and blood system in broiler chickens (Gallus domesticus). Acta Veterinaria Brno, 76(8): 17-23. Google Scholar I Doi: https://doi.org/10.2754/avb200776S8S017

Bogosavljević-Bosković S., Kurćubić V., Petrović M., Dosković V. (2006): The effects of season and rearing systems on meat quality traits. Czech Journal of Animal Science, 51: 369-374. Google Scholar I https://doi.org/10.17221/3953-CJAS

Chen H, Huang RL, Zhang HX, Di KQ, Pan D, and Hou YG (2007). Effects of photoperiod on ovarian morphology and carcass traits at sexual maturity in pullets. Poultry Science, 86(5): 917-920. Google Scholar I Doi: https://doi.org/10.1093/ps/86.5.917

Crounch AN, Grimes JL, Christensen VL, and Kruegert KK (2002). Effect of physical restriction during rearing on large white turkey breeder hens. 3. Body and carcass composition. Poultry Science, 81(12): 1792-1797. Google Scholar I Doi: https://doi.org/10.1093/ps/81.12.1792

De Beer M, and Coon CN (2007). The effect of different feed restriction programs on reproductive performance, efficiency, frame size, and uniformity in broiler breeder hens. Poultry Science, 86(5): 1927-1939. Google Scholar I Doi: https://doi.org/10.1093/ps/86.9.1927

Farghly M, Mahrose K, Ahmad E, Rehman Z and Yu, S. (2019). Implementation of different feeding regimes and flashing light in broiler chicks. Poultry Science, 98(5): 2034-2042. Google Scholar I Doi: https://doi.org/10.3382/ps/pey577

Hassanabadi A, and Moghaddam HN (2004). Effect of early feed restriction on performance characteristics and serum thyroxin of broiler chickens. International Journal of Poultry Science, 5 (12): 1156-1159. Google Scholar I Doi: https://doi.org/10.3923/ijps.2006.1156.1159

Persia ME, Utterback PL, Biggs PE, Koelkebeck KW, and Parson CM (2003). Interrelationship between environmental temperature and dietary nonphytate phosphorus in laying hens. Poultry Science, 82(11): 1763-1768. Google Scholar I Doi: https://doi.org/10.1093/ps/82.11.1763

Renema RA, Robinson FE, and Zuidhof MJ (2007). Reproductive efficiency and metabolism of female broiler breeders as affected by genotype, feed allocation, and age at photo stimulation. 2. Sexual maturation. Poultry Science, 86(10): 2267-2277. Google Scholar I Doi: https://doi.org/10.1093/ps/86.10.2267

Renema RA, Robinson FE, Newcombe M, and McKay RI (1999). Effect of body weight and feed allocation during sexual maturation in broiler breeder hens. 1. Growth and carcass characteristics. Poultry Science, 78(5): 619-628. Google Scholar I Doi: https://doi.org/10.1093/ps/78.5.619

Robinson, F. E., N. A. Robinson, and T. A. Scott, 1991.Reproductive performance, growth rate and body composition of full-fed versus feedrestricted broiler breeder hens. Canadian Journal of Animal Science, 71:549-556. Google Scholar I Doi: https://doi.org/10.4141/cjas91-065

Rosa PS, Faria Filho DE, Dahlke F, Viera BS, Macari M, and Furlan RL (2007). Performance and carcass characteristics of broiler chickens with different growth potential and submitted to heat stress. Brazilian Journal of Poultry Science, 9(3): 181-186. Google Scholar I Doi: https://doi.org/10.1590/S1516-635X2007000300007

Van Marle-Köster E and Webb EC (2000). Carcass characteristics of South African native chicken lines. South African Journal of Animal Science, 30(1): 53-56. Google Scholar I Doi: https://doi.org/10.4314/sajas.v30i1.3876

Zaboli G, Huang X, Feng X, and Ahn DU (2019). How can heat stress affect chicken meat quality? - a review. Poultry Science, 98(3): 15511556. Google Scholar I Doi: https://doi.org/10.3382/ps/pey399 